\title{
The Surgical Management of Haemorrhoids - A Review
}

\author{
A. Hardy C.L.H. Chan C.R.G. Cohen \\ St. Mark's Hospital, Harrow, UK
}

\section{Key Words}

Classification, haemorrhoids · Haemorrhoids, aetiology • Surgical management, haemorrhoids

\begin{abstract}
A number of new surgical treatments have led to a reappraisal of haemorrhoid disease over the last few decades. Despite a range of treatment modalities, the options are limited in their effectiveness and can lead to a number of complications. An inadequate classification system based on appearance rather than symptoms makes the choice of appropriate therapy difficult. More recent techniques have led to a move away from surgical excision. However, further research is required to establish their precise indications and long-term efficacy.
\end{abstract}

Copyright () 2005 S. Karger AG, Basel

Haemorrhoids have been treated by surgeons for centuries. Therapies for the topical treatment of haemorrhoids date back to Egyptian papyri of 1700 BC. The first surgical treatment was described in the Hippocratic Treatises of $460 \mathrm{BC}$, and suggested 'transfixing them with a needle and tying them with a very thick and large woollen thread [1].' Despite centuries of treating the condition, its precise aetiology is unclear and a definitive treatment has yet to be established. It is a condition with a variety of symptoms and a spectrum of severity. The large number of treatment options reflects this.

\section{KARGER \\ Fax +4161306 1234 E-Mailkarger@karger.ch} www.karger.com
(C) 2005 S. Karger AG, Basel 0253-4886/05/0222-0026\$22.00/0

Accessible online at: www.karger.com/dsu
Haemorrhoids affect between 4.4 and $36.4 \%$ of the general population [2]. Only in the last 30 years have anatomical [3] and histological [4] studies been used to characterise their anatomy and aetiology [2]. This has led to a resurgence in interest in the condition, associated with the development of a number of novel treatments. Nevertheless, the surgical management of haemorrhoids is often based more on anecdote than science. Many myths continue to perpetuate in both lay and professional circles.

\section{Aetiology and Classification}

Prior to work in 1975, the rich plexus of blood vessels in the anal submucosa was thought to form a continuous ring of erectile tissue around the anal canal. This was known to contribute to the continence mechanism [5]. Thomson was the first to introduce the concept of 'anal cushions', usually 3 in number, found in the left lateral, right anterior and right posterior positions (or classical 3, 7 and 11 o'clock positions) [3].

The bulk of the anal cushions sits above the dentate line. They are therefore lined with relatively insensate mucosa. Between this and the internal sphincter lies the submucosal layer, consisting of vascular, muscular and connective tissue elements. This layer is thought to be central to the understanding of both the aetiology and the treatment of haemorrhoids. Below and continuous with the submucosa is the inferior haemorrhoidal plexus. At 
the anal verge, this can become engorged in continuity with the internal plexus, giving an external component to the haemorrhoids. A careful distinction between prolapsing internal haemorrhoids, and external haemorrhoids and their skin tag remnants may have implications for the choice of treatment.

The internal anal sphincter is not solely responsible for the closure of the anal canal [6]. The blood-filled mucosal cushions are required to give a 'watertight' seal. Excision of the anal cushions at haemorrhoidectomy is known to impair continence to infused saline [7]. The ability of the anal cushions to alter their volume through their vascular component allows for both the preservation of continence and the passage of stool. Vascular filling is thought to contribute between 15 and $20 \%$ of resting anal pressure [8].

The vascular anatomy of the anal cushions inspired many of the original theories of haemorrhoid aetiology. The suggestion that a local increase in pressure caused venous dilations within the anal cushions [9] was initially favoured. It appeared to explain the known associations between pregnancy and haemorrhoids, and constipation and straining as an aetiology [10]. The absence of valves in the portal venous system and the portosystemic anastomoses within the anal canal lent support to a venous pressure theory. The concept of rectal varices also led to some confusion, but this is now known to be a separate clinical entity [11]. Studies have shown that there are indeed tiny discrete dilations of the venous plexus, but that these form part of the normal anatomy and are not a pathological phenomenon [3]. There is no known association between haemorrhoids and varicose veins, or varicoceles [12].

Despite their vascular appearance and tendency to bleed, the development of haemorrhoids may be due to a connective tissue disorder. Histologically, the connective tissue (mainly collagenous) fibres of the submucosa anchor the anal cushions to the underlying internal sphincter and conjoined longitudinal muscle. With age this supportive meshwork degenerates and the anal cushion is displaced caudally, possibly assisted by straining and the passage of stool [4]. This may account for haemorrhoidal prolapse. Fixation of this tissue is the basis of a number of surgical treatments.

Why haemorrhoids bleed is a separate question. Prolapsed anal cushions may bleed intermittently, often associated with defecation. However, bleeding and prolapse need not coexist. Some patients have prolapsed haemorrhoids which do not bleed (mostly lined with mucosa showing signs of squamous metaplasia.) Other patients have bleeding with no prolapse. This may be a re- sult of localised mucosal trauma and damage to the underlying vasculature. Arteriovenous anastomoses within the submucosa are thought to contribute to the increase in volume of the anal cushions, sealing the anal canal [3]. This arterial component explains why haemorrhoidal bleeding has the appearance and $\mathrm{pH}$ of arterial blood [13].

Anal cushions which become symptomatic through bleeding or prolapse are termed haemorrhoids. This can lead to a number of secondary symptoms such as pain, pruritis and mucus discharge. The correlation between these symptoms and the appearance of the haemorrhoids is poor. Apparently severe looking haemorrhoids can cause relatively few symptoms. By contrast, normal looking anal cushions can give rise to symptoms which cause great anxiety. Socioeconomic, cultural and educational factors all have a role to play.

A haemorrhoid classification system is useful not only to help choose from the various treatments, but also to compare them. The most widely used, the Goligher classification, describes four grades or degrees based on the appearance of the haemorrhoids. First-degree haemorrhoids bleed but do not prolapse (i.e. normal looking anal cushions causing symptoms.) Second-degree haemorrhoids bleed and prolapse, but reduce spontaneously after defaecation. Third-degree haemorrhoids need to be reduced manually, and fourth-degree are permanently prolapsed at the anal verge and cannot be reduced. This classification is inadequate for a number of reasons. It assumes that bleeding and prolapse are the only symptoms, and that there is a direct correlation between these symptoms and the appearance of the haemorrhoids. It may also tempt the surgeon to neglect the primary aim - to relieve symptoms - at the expense of restoring normal anatomy. Classification systems based on symptoms alone are unwieldy, and ignore the fact that many perianal symptoms blamed on 'piles' are in fact due to other pathologies.

The Goligher classification is helpful if used with an awareness of its limitations. The surgeon must distinguish between prolapsing and non-prolapsing haemorrhoids, and if they are prolapsing, determine whether they are second, third or fourth degree. Are they single, multiple or circumferential? This too may influence the treatment choice. An appreciation of the external component of the haemorrhoids is also important, as this may contribute to symptoms and alter management options. 


\section{Conservative Treatments}

Conservative measures may prevent the need for any surgical intervention, or delay its timing. Often all the patient requires, following appropriate endoscopic evaluation, is reassurance that their symptoms have a benign cause. Other measures concentrate on the prevention of constipation and straining, and the topical application of creams and ointments to relieve pain and pruritis. Unfortunately the evaluation of such treatments in clinical trials is limited. Certainly many patients find these measures temporarily effective, but these have often been tried before their outpatient assessment.

The role of constipation in the aetiology of haemorrhoids is controversial. Burkitt's 'dietary fibre hypothesis' postulated that the low incidence of haemorrhoids in rural Africa was due to the high fibre diet compared to the developed world [10]. Other studies refute this. Although there was a progressive decline in the occurrence of haemorrhoids over the last 30 years in Britain and the US, there was no corresponding increase in dietary fibre intake [14]. Certainly there is an association between haemorrhoids and constipation, but it is equally likely that it is the haemorrhoids which are responsible for the constipation and not vice versa $[15,16]$. Dietary advice, stool softeners and laxatives are helpful to discourage straining, which is thought to be a risk factor. Indeed this may be as effective as invasive treatments and all that is required [17].

\section{Outpatient Treatments}

\section{Injection}

Injection sclerotherapy is often used as a first-line outpatient procedure for first and second-degree haemorrhoids. A small quantity of the sclerosant solution is injected submucosally into the base of the haemorrhoid. This is thought to induce a local inflammatory reaction, shrinking the haemorrhoidal mass and causing fixation of the mucosa to the underlying muscle. The most popular sclerosant is $5 \%$ phenol in almond oil, and if administered correctly into the base of each haemorrhoid in turn above the dentate line, should cause minimal discomfort. Other sclerosants have been described, but there are no studies comparing their efficacies [18]. Injection sclerotherapy can stop bleeding from haemorrhoids, but is unhelpful in treating prolapse. It has the advantage that it is cheap, easily taught, virtually painless and relatively safe. Its disadvantage is the high failure rate, and the apparent need for further treatment.
According to a questionnaire concerning 100 patients who had undergone outpatient sclerotherapy for first-degree haemorrhoids, $62 \%$ had no bleeding at $24 \mathrm{~h}$. At 28 days that figure had fallen to $41 \%$, although overall $88 \%$ felt their symptoms had improved [19]. A randomised controlled trial of 43 patients given either sclerotherapy or bulk laxatives alone showed no significant difference in symptoms of bleeding at 6 months [17]. This work has been confirmed by others [20]. Other work has shown that injections do benefit the patient, but that a single session using an adequate dose ( $5 \mathrm{ml}$ of $5 \%$ phenol in each haemorrhoid) is as effective as multiple injections of a smaller dose [21]. Longer-term results show an improvement in $40 \%$ of patients at 4 years, but with $20 \%$ subsequently complaining of prolapse [22].

Complications of sclerotherapy are rare, but usually result from an injection placed too deeply, especially anteriorly in the male. Urinary retention, prostatitis, prostatic abscess, epididymo-orchitis have all been reported [23]. Cases of life-threatening sepsis also exist [24].

In summary, with good technique and careful case selection, injection sclerotherapy may be an effective shortterm treatment for bleeding first and early second-degree haemorrhoids. However, many patients will require further treatment. Multiple injections have not been shown to confer any benefit.

\section{Photocoagulation}

Infrared coagulation techniques for the thermal ablation of haemorrhoids were first described by Neiger in 1977. Photocoagulation has the advantage over other outpatient methods that the effects on the tissues of the anal canal are controlled and reproducible [25]. Varying the optical wavelength of the coagulator or the contact time varies the depth of penetration into the tissues. The infrared coagulator gun is set to between 1.0 and $1.5 \mathrm{~s}$. Through a proctoscope the base of the haemorrhoid is identified in the same way as for sclerotherapy. Three areas of coagulation are recommended at the base of the haemorrhoid in a triangular shape. Photocoagulation creates a constant depth of necrosis. This area (seen as a white spot after the procedure) forms an ulcer, and ultimately an area of mucosal tethering, with associated shrinkage of the haemorrhoidal mass. Results for nonprolapsing haemorrhoids appear to show that this is a superior technique to injection sclerotherapy [26]. Certainly it is less 'technique dependent' and avoids the potential complications of misplaced injections. Although larger, prolapsing haemorrhoids may not respond as well to this technique, photocoagulation provides a safe, rapid 
and non-invasive alternative to other outpatient procedures. Its use may be limited by the availability and expense of the equipment.

\section{Cryotherapy}

This technique of ablating the haemorrhoid mass with a freezing 'cryoprobe' enjoyed popularity some decades ago but has currently fallen out of favour because of mixed results [27]. The surgeon has little control over the depth or area of tissue affected. This can lead to pain, bleeding and delayed healing, with the subsequent ulceration leading to a profuse discharge.

\section{Banding}

Ligation of the haemorrhoidal mass has been the basis of many haemorrhoidal treatments over the centuries [1] Obliteration of the vessels 'feeding' the haemorrhoid leads to ulceration and sloughing, with subsequent healing over a period of weeks. Barron modified the technique with small rubber bands, initially cut from slices of a urinary catheter [28]. The haemorrhoid mass is grasped with an Allis forceps passing through the banding apparatus, and the rubber band is 'fired' round the base of the haemorrhoid. Some devices use suction to pull down the haemorrhoidal tissue. It is imperative, as with the position of sclerotherapy injections, to identify the level of the dentate line and carry out the procedure above this level. Barron originally advocated the ligation of one haemorrhoid at a time, with future bandings at 3-week intervals. Studies have shown, however, that there is no significant increase in patient discomfort, or the predicted problems of anal stenosis, with multiple bandings in a single session [29]. Smaller studies have not demonstrated any advantage of rubber band ligation over phenol sclerotherapy [30]. Larger trials [31] and meta-analysis [32] show rubber band ligation to be both more effective and less likely to require further therapy than injection. This is shown for first and second-degree haemorrhoids as well as third. Such meta-analysis has also shown banding to be superior to photocoagulation. One study suggested that in spite of its greater long-term efficacy, the high incidence of post-treatment pain may favour photocoagulation as the optimal outpatient therapy [33]. Overall, it appears that between 60 and $80 \%$ of patients who have undergone banding are satisfied with the outcome.

Complications of banding can occur in up to $14 \%$ of patients, most commonly pain and haemorrhage. The hospital readmission rates are put at between 1.2 and $2.5 \%$ [23]. With occasional reports of life-threatening bleeding or pelvic sepsis [34], the relative merits of band- ing as a non-operative treatment must be set against the higher potential complication rate.

\section{Operative Treatments}

\section{Open and Closed Haemorrhoidectomy}

The surgical excision of haemorrhoids has been popular for centuries. Parks [1] felt it was the relative resistance of the anal canal to infection which explained the enthusiasm for operations of this sort. Until the development of the stapled haemorrhoidopexy at the end of the 20th century, surgical excision and its variants were the only options for the treatment of prolapsed haemorrhoids which had failed to respond to less radical measures.

Whitehead's procedure was first described in 1882 . He advocated a circumferential excision of the anal cushions, anastomosing the anoderm to the rectal mucosa. This operation was viewed with suspicion by some surgeons due to its significant risk of complications, including excessive blood loss, mucosal ectropion and stricture formation ('Whitehead deformity'). This led to a search for a safer alternative. Most popular amongst these have been the Milligan-Morgan haemorrhoidectomy, favoured by most UK surgeons, and the closed haemorrhoidectomy, popular in the United States. The Whitehead procedure still has its advocates, however. In a series of 356 patients who had undergone Whitehead's procedure, 5 patients had a symptomatic stricture [35]. Care had been taken to carry out the procedure above the dentate line and to recreate the mucocutaneous junction by incorporating the internal sphincter into the suture line. It was suggested in this study that a misunderstanding of the anatomy of the dentate line may have been responsible for poor results earlier in the century. Another study of nearly 500 patients followed up over 3 years showed a $6.9 \%$ incidence of flap breakdown, but no recurrences, ectropian or stricture formation [36]. So-called 'total haemorrhoidectomy' such as this may have its place in the management of circumferential haemorrhoids, but in the majority of cases the safer 'Milligan-Morgan' alternative, retaining skin bridges, is thought to be safer. The stapled haemorrhoidopexy has largely superseded these older techniques for the management of circumferential and fourth-degree haemorrhoids.

Milligan and Morgan wrote their classic paper on open haemorrhoidectomy, an 'excision-ligation' procedure for haemorrhoids, in 1937 [37]. This has been subject to numerous modifications over the years, and more recently adapted by the use of diathermy [38], laser [39], ligasure 
[40], and harmonic scalpel [41]. The underlying principle of open haemorrhoidectomy is the preservation of skin bridges between the excised haemorrhoids to prevent stricturing. It remains the same regardless of the instruments of excision used. Wounds are left to heal by secondary intention.

In the closed haemorrhoidectomy, first described by Ferguson in 1959 [42], the haemorrhoidal plexus is filleted from the overlying mucosa, and the wounds closed primarily with an absorbable suture. Healing is felt by some to be faster and less painful after this latter procedure. In a recent study 100 patients were randomised to either open or closed procedures. Although results were similar after a year, healing and pain scores were improved in the closed haemorrhoidectomy group [43] Other studies dispute this, with one showing a significant number of patients in the 'closed' group taking longer to heal due to wound dehiscence [44].

Haemorrhoidectomy is not without complications. Foremost amongst these is pain, with most studies recording pain scores and the time taken to resume work and normal activities. A number of adjuncts to the haemorrhoidectomy procedure have been tried. Local anaesthetic combined with adrenaline (for example $20 \mathrm{ml}$ of $0.25 \%$ bupivicaine with $1: 200,000$ adrenaline) helps both pain control and provides a drier operating field due to its vasoconstrictor action. Some units use low spinal, caudal or epidural anaesthesia either as an addition to, or substitute for a general anaesthetic. Spasm of the internal sphincter is thought to play an important role in pain after haemorrhoidectomy [9]. There is no evidence that simultaneous internal sphincterotomy is helpful [45], and indeed this may lead to long-term sequelae of mild incontinence in $22 \%$ of patients [46]. 'Chemical sphincterotomy' by the application of topical $0.2 \%$ GTN post-operatively appears to confer no benefit, although it may effect more rapid wound healing [47]. Recently, botulinum toxin has been shown to improve pain in the first post-operative week [48], but the sample size was small and the difference to placebo marginal.

The role of local sepsis as a cause for pain in the weeks following haemorrhoidectomy is poorly understood. A 1week course of metronidazole has been shown to improve pain scores and patient satisfaction in open haemorrhoidectomy [49], but not in the closed procedure [50], possibly supporting secondary infection as a causative factor.

Non-steroidal anti-inflammatory drugs have been shown to be as effective as and safer than opioid analgesics after haemorrhoidectomy [51]. The use of stool softeners such as lactulose is well established to help avoid straining, and ease the pain of the first post-operative bowel motion. It has been suggested that starting this four days prior to the operation may be beneficial [52]. The avoidance of bulky packs and dressings in the anal canal is also known to reduce post surgical pain [53].

Adequate perioperative pain relief helps avoid the complication of urinary retention. Urinary symptoms (retention or infection) were found to affect $20.1 \%$ of patients after haemorrhoid surgery in one large study [54]. The overenthusiastic use of intravenous fluids during the procedure may contribute to the high incidence of urinary retention [55], as will spinal anaesthesia.

Bleeding in the immediate-post operative period is almost always due to inadequate intraoperative haemostasis. Delayed haemorrhage occurs in $2.4 \%$ of cases at between 7 and 14 days [54].

An operation involving the removal of the anal cushions might be expected to impair continence. This may be transient, until other factors compensate, or it may be longer lasting. A study of over 400 patients after haemorrhoidectomy found 33\% reported impaired continence following the procedure [56]. Anal strictures can arise as a result of surgeons failing to leave adequate mucosal bridges between excised haemorrhoids. This has been reported in up to $3.8 \%$ of haemorrhoidectomies [57]. They responded to outpatient dilatation, or a further corrective procedure such as lateral internal sphincterotomy or anoplasty [57].

Although 5\% of patients have been found to have transient bacteraemias following diathermy haemorrhoidectomy [58], septic complications of either the open or closed procedures are very rare. The infrequent cases of fulminant perineal sepsis tend to have other risk factors involved, such as immunosuppressive therapies [23]. Suturing the wounds closed in a Ferguson procedure does not appear to confer any benefit.

\section{Doppler-Guided Haemorrhoidal Artery Ligation}

As newer techniques for treating haemorrhoids are developed, the emphasis has shifted away from excision procedures and the possible resulting pain and complications. Doppler-guided ligation of the haemorrhoidal artery (DGHAL) was first described in 1995, and has become increasingly popular in Europe [59].

Thomson's [3] studies of the haemorrhoidal branches of the superior rectal artery showed an average of 5 branches reaching the anal cushions. DGHAL uses a specially adapted proctoscope with an incorporated Doppler probe. This is inserted and used to locate the haemorrhoidal arteries by an audible alteration in signal. Once 
located, a needleholder is inserted into the lumen of the proctoscope and the artery ligated with a 'figure of eight' absorbable suture into the submucosa. The procedure is repeated until no more Doppler signals are identified. DGHAL both disrupts the arterial inflow and tethers the mucosa, causing the haemorrhoidal mass to shrink and retract. Currently the procedure tends to be carried out under general anaesthetic, but some patients are able to tolerate it under sedation.

Early results seem to indicate this is most effective for grade 3 haemorrhoids. In a series of 308 patients of grade 2-4 symptomatic haemorrhoids, 60\% were asymptomatic at 18 months. There were no major complications and pain relief requirements were minimal ( $26 \%$ required diclofenac for the first to the third post-operative day [Arnold, Scheyer, unpubl. data].) Further research is needed, but these results appear to suggest it lies somewhere between banding and haemorrhoidectomy in the hierarchy of treatments - offering a more effective alternative to banding without the mutilation of haemorrhoidectomy.

\section{Stapled Haemorrhoidopexy}

The development of the stapled haemorrhoidopexy (or procedure for prolapsing haemorrhoids - $\mathrm{PPH}$ ) was the first attempt to deal with the problem of haemorrhoidal prolapse without recourse to excision or ligation of the haemorrhoidal masses. A recent consensus document acknowledged this by recommending the term 'stapled haemorrhoidopexy' rather than 'haemorrhoidectomy' [60]. The device, developed by Longo in the 1990s, reduces prolapse by a circular stapled mucosectomy $4 \mathrm{~cm}$ above the dentate line [61]. This not only shortens the prolapsing mucosa (and thus reduces the haemorrhoids) but is also thought to disrupt the branches of the haemorrhoidal artery which feed the anal cushions. Early results of this technique were questioned, with some series reporting complications of pain and urgency [62]. With refinement and improved technique it has been shown to be both an effective and considerably less painful alternative to haemorrhoidectomy for prolapsing grade 3 and 4 haemorrhoids [63]. As a procedure which avoids excision of the anal cushions it also has the advantage that it restores anatomy more closely to its premorbid state.

Over fifteen randomised controlled trials have contrasted this new technique with the established open, closed and diathermy haemorrhoidectomies. Pooled data shows no discernable difference in operating time between the procedures, but this may change as the technique becomes more established. It did confirm, however, reduced pain in the 10 days following the $\mathrm{PPH}$ procedure and an earlier return to normal activities [63]. Longer term data from the trials are less readily available. One study of 30 patients followed up at 6 months showed that $69 \%$ in the diathermy group were asymptomatic, but only $36 \%$ of the stapled group were symptom free [64]. Another trial reviewed 36 of the original 40 trial patients after a minimum of 33 months. No significant difference was seen between the excision and stapled groups in symptomatic and functional outcome, or quality of life [65]. Both trials acknowledged the problems of residual symptoms caused by external haemorrhoids and skin tags not dealt with by the stapled haemorrhoidopexy procedure.

The stapling procedure has its own unique set of complications. The depth and height of the purse-string suture appears critical to ensure an adequate 'doughnut' of mucosa is removed and the staple line lies at an appropriate height [62]. Concern about incorporation of smooth muscle in the ring of tissue removed may have few consequences for the majority of patients [66], but show the potential for catastrophic complications if a leak from the staple line results. Rectal perforation and rectovaginal fistulae have been reported [23], and a survey of 4,635 stapled haemorrhoid procedures in Germany found 3 rectal perforations and 1 death from Fournier's gangrene [67]. Bleeding complications are thought to be fewer with the stapled technique, and anal stenosis and stricture do not appear to be a particular complication of the stapled haemorrhoidopexy [63].

With careful technique and patient selection, the stapled haemorrhoidopexy offers another treatment option for prolapsing haemorrhoids. In spite of its early promise of reduced pain in the immediate post-operative period compared with excision haemorrhoidectomy, it is not without its own complications. These risks must be addressed when advising patients and selecting the appropriate procedure.

\section{Conclusion}

New techniques in the surgical management of haemorrhoids have led to a more recent critical appraisal of both the aetiology and classification of this condition. The Goligher classification offered 'degrees' of haemorrhoid appearance to which a hierarchy of treatments could be applied. With more attention to the patient's symptoms and expectations of treatment, however, the appropriate intervention can be matched to the severity of the problem. Offering injection sclerotherapy routinely to a pa- 
tient with grade 1 haemorrhoids may not be appropriate. The patient with bleeding but no prolapse may be satisfied with reassurance that they do not have cancer and require no further treatment other than dietary advice. A stapled haemorrhoidopexy may not help a patient with grade 4 haemorrhoids. An appreciation of the external component of the haemorrhoids and any associated skin tags may be relevant to whether the PPH procedure will give the result the patient expects. Some patients are happy to go through a number of minor procedures to avoid the pain and inconvenience of a major one. Other patients will endure anything as long as a definitive solution is possible. Haemorrhoids, although inconvenient to many, are a benign condition. The potential for complications after surgical treatment is small, but remains significant. It is not a condition that lends itself to treatment protocols.

There remain a number of unanswered questions concerning the aetiology and treatment of haemorrhoids. The literature, though extensive, is often based on small studies, with poorly defined outcome measures. As more treatments emerge, so the need to evaluate by proper randomised trial increases. An appreciation of this literature, as well as familiarity with the various treatment techniques, is essential if the patient is to be treated based on evidence rather than anecdote and tradition.

\section{References}

1 Parks AG: De Haemorrhoids: A study in surgical history. Guys Hosp Rep 1955; 104:135156.

$\checkmark 2$ Loder PB, Kamm MA, Nicholls RJ, Phillips RKS: Haemorrhoids: Pathology, pathophysiology and aetiology. Br J Surg 1994;81:946954

-3 Thomson WHF: The nature of haemorrhoids. Br J Surg 1975;65:542-552.

$\checkmark 4$ Haas PA, Fox TA, Haas GP: The pathogenesis of hemorrhoids. Dis Colon Rectum 1984;27: $442-450$.

5 Stieve H: Über die Bedeutung venöser Wundnetze für den Verschluss einzelner Öffnungen des menschlichen Körpers. Dtsch Med Wochenschr 1928:54:87-90, 130-133.

6 Gibbons CP, Trowbridge EA, Bannister JJ, Read NW: Role of anal cushions in maintaining continence. Lancet 1986;i:886-888.

7 Read MG, Read NW, Haynes WG, Donnelly TC, Johnson AG: A prospective study of the effect of haemorrhoidectomy on sphincter function and faecal continence. Br J Surg 1982; 69:396-398.

8 Lestar B, Penninckx F, Kerremans R: The composition of anal basal pressure. An in vivo and in vitro study in man. Int $\mathrm{J}$ Colorectal Dis 1989;4:118-122.

-9 Parks AG: The surgical treatment of haemorrhoids. Br J Surg 1956;43:337-351.

10 Burkitt DP: Varicose veins, deep vein thrombosis, and haemorrhoids: Epidemiology and suggested aetiology. BMJ 1972;ii:556-561.

-11 McCormack TT, Bailey HR, Simms JM, Johnson AG: Rectal varices are not piles. Br J Surg 1984;71:163.

-12 Denis J: Etude numérique de quelques facteurs étiopathogéniques des troubles hémorrhoidaires de l'adulte. Arch Fr Mal App Dig 1976; 65:529-536.
13 Thulesis Ø, Gjöres JE: Arterio-venous anastomosis in the anal region with reference to the pathogenesis and treatment of haemorrhoids. Acta Chir Scand 1973;139:476-478.

14 Johanson JF, Sonnenberg A: Temporal changes in the occurrence of haemorrhoids in the United States and England. Dis Colon Rectum 1991;34:585-591.

15 Gibbons CP, Bannister JJ, Read NW: Role of constipation and anal hypertonia in the pathogenesis of haemorrhoids. Br J Surg 1988;75: 656-660.

16 Johanson JF, Sonneberg A: The prevalence of haemorrhoids and chronic constipation. An epidemiologic study. Gastroenterology 1990; 98:380-386.

17 Senapati A, Nicholls RJ: A randomised trial to compare the results of injection sclerotherapy with a bulk laxative alone in the treatment of bleeding haemorrhoids. Int $\mathrm{J}$ Colorectal Dis 1988:3:124-126.

18 Ponsky JL, Mellinger JD, Simon IB: Endoscopic retrograde haemorrhoidal sclerotherapy using 23.4\% saline: A preliminary report. Gastrointest Endosc 1991;37:155-158.

19 Mann CV, Motson R, Clifton M: The immediate response to injection therapy for first-degree haemorrhoids. J R Soc Med 1988;81:146148.

20 Broader JH, Gunn IF, Alexander-Williams J: Evaluation of a bulk-forming evacuant in the management of haemorrhoids. Br J Surg 61: 142.

21 Khoury GA, Lake SP, Lewis MC, Lewis AA: A randomised trial to compare single with multiple phenol injection treatment for haemorrhoids. Br J Surg 1985; 72:741-742.

22 Porrett TR, Lunniss PJ: A prospective randomised controlled trial of consultant-led sclerotherapy compared with nurse practitioner-led non-invasive interventions in the treatment of patients with first and second-degree haemorrhoids. Colorectal Dis 2001;3:227231 .
23 Guy RJ, Seow-Choen F: Septic complications of haemorrhoids. Br J Surg 2003;90:147-156.

24 Barwell J, Watkins RM, Lloyd-Davies E, Wilkins DC: Life-threatening sepsis after haemorrhoid injection sclerotherapy: Report of a case. Dis Colon Rectum 1999;42:421423.

25 Leicester RJ, Nicholls RJ, Mann CV: Infrared coagulation: A new treatment for haemorrhoids. Dis Colon Rectum 1981;24:602-605.

-26 Walker AJ, Leicester RJ, Nicholls RJ, Mann $\mathrm{CV}$ : A prospective study of infrared coagulation, injection and rubber band ligation in the treatment of haemorrhoids. Int J Colorectal Dis 1990;5:113-116.

$>27$ Oh C: One thousand cryohaemorrhoidectomies: An overview. Dis Colon Rectum 1981; 24:613-617.

28 Barron J: Office ligation of haemorrhoids. Dis Colon Rectum 1963;6:109-113.

29 Khubchandani IT: A randomised comparison of single and multiple rubber band ligations. Dis Colon Rectum 1983;26:705-708.

30 Greca F, Hares MM, Nevah E, Alexander-Williams J, Keighley MR: A randomized trial to compare rubber band ligation with phenol injection for treatment of haemorrhoids. $\mathrm{Br} \mathrm{J}$ Surg 1981;68:250-252.

-31 Gartell PC, Sheridan RJ, McGinn FP: Outpatient treatment of haemorrhoids: A randomized clinical trial to compare rubber band ligation with phenol injection. Br J Surg 1985;72: 478-489.

32 MacRae HM, McLeod RS: Comparison of hemorrhoidal treatment modalities: A metaanalysis. Dis Colon Rectum 1995; 38:687694.

33 Johanson JF, Rimm A: Optimal nonsurgical treatment of hemorrhoids: A comparative analysis of infrared coagulation, rubber band ligation, and injection sclerotherapy. Am J Gastroenterol 1992;87:1600-1606. 
34 O'Hara VS: Fatal clostridial infection following haemorrhoidal banding. Dis Colon Rectum 1980;23:570-571.

- 35 Bonello JC: Who's afraid of the dentate line? The Whitehead hemorrhoidectomy. Am J Surg 1988;156:182-186.

-36 Wolff BG, Culp CE: The Whitehead hemorrhoidectomy. An unjustly maligned procedure. Dis Colon Rectum 1988;31:587-590.

37 Milligan ETC, Morgan CN, Officer R: Surgical anatomy of the anal canal, and the operative treatmentofhaemorrhoids.Lancet 1937; ii:119124.

- 38 Andrews BT, Layer GT, Jackson BT, Nicholls $\mathrm{RJ}$ : Randomized trial comparing diathermy hemorrhoidectomy with the scissor dissection Milligan-Morgan operation. Dis Colon Rectum 1993;36:580-583.

- 39 Wang JY, Chang-Chien CR, Chen JS, Lai CR, Tang R: The role of lasers in hemorrhoidectomy. Dis Colon Rectum 1991;34:78-82.

-40 Jayne DG, Botterill I, Ambrose NS, Brennan TG, Guillou PJ, O'Riodain DS: Randomized clinical trial of ligasure versus conventional diathermy for day-case haemorrhoidectomy. Br J Surg 2002;89:428-432.

41 Tan JJ, Seow-Choen F: Prospective, randomised trail comparing diathermy and Harmonic Scalpel hemorrhoidectomy. Dis Colon Rectum 2001;44:677-679.

-42 Ferguson DJ, Heaton JR: Closed hemorrhoidectomy. Dis Colon Rectum 1959;2:176-179.

-43 Arroyo A, Perez F, Miranda E, Serrano P, Candela F, Lacueva J, Hernandez H, Calpena R: Open versus closed day-case haemorrhoidectomy: Is there any difference? Results of a prospective randomised study. Int $\mathrm{J}$ Colorectal Dis 2004;19:370-373.

-44 Ho YH, Seow-Choen F, Tan M, Leong AF: Randomized controlled trial of open and closed haemorrhoidectomy. Br J Surg 1997;84: 1729-1730.

-45 Khubchandani IT: Internal sphincterotomy with hemorrhoidectomy does not relieve pain: A prospective, randomised study. Dis Colon Rectum 2002;45:1452-1457.

46 Khubchandini IT, Reed JR: Sequelae of internal sphincterotomy for chronic fissure in ano. Br J Surg 1989;76:431-434.
47 Hwang do Y, Yoon SG, Kim HS, Lee JK, Kim KY: Effect of 0.2 percent glyceryl trinitrate ointment on wound healing after a hemorrhoidectomy: Results of a randomized, prospective, double-blind, placebo-controlled trial. Dis Colon Rectum 2003;46:950-954.

48 Davies J, Duffy D, Boyt N, Aghahoseini A, Alexander D, Leveson S: Botulinum toxin (botox) reduces pain after hemorrhoidectomy: Results of a double-blind, randomized study. Dis Colon Rectum 2003;46:1097-1102.

49 Carapeti EA, Kamm MA, McDonald PJ, Phillips RKS: Double-blind randomised controlled trial of effect of metronidazole on pain after day-case haemorrhoidectomy. Lancet 1998; 351:169-172.

-50 Balfour L, Stojkovic SG, Botterill ID, Burke DA, Finan PJ, Sagar PM: A randomized, double-blind trial of the effect of metronidazole on pain after closed hemorrhoidectomy. Dis Colon Rectum 2002;45:1186-1190.

51 O’Donovan S, Ferrara A, Larach S, Williamson P: Intraoperative use of Toradol facilitates outpatient hemorrhoidectomy. Dis Colon Rectum 1994;34:793-799.

52 London NJ, Bramley PD, Windle R: Effect of four days of preoperative lactulose on posthaemorrhoidectomy pain: Results of a placebo-controlled trial. Br Med J (Clin Res Ed) 1987;295:363-364.

53 Ingram M, Wright TA, Ingoldby CJ: A prospective randomized study of calcium alginate (Sorbsan) versus standard gauze packing following haemorrhoidectomy. J R Coll Surg Edinb 1998;Oct 43:308-309.

54 Bleday R, Pena JP, Rothenberger DA, Goldberg SM, Buls JG: Symptomatic hemorrhoids: Current incidence of complications of operative therapy. Dis Colon Rectum 1992;35:477481.

55 Bailey HR, Ferguson JA: Prevention of urinary retention by fluid restriction following anorectal operations. Dis Colon Rectum 1976;19: 250-252.

-56 Johannsson HO, Graf W, Pahlman L: Longterm results of haemorrhoidectomy. Eur J Surg 2002;168:485-489.

57 Eu KW, Teoh TA, Seow-Choen F, Goh HS: Anal stricture following haemorrhoidectomy: Early diagnosis and treatment. Aust NZ J Surg 1995;65:101-103.
58 Maw A, Concepcion R, Eu KW, Seow-Choen F, Heah SM, Tang CL, Tan AL: Prospective randomized study of bacteraemia in diathermy and stapled haemorrhoidectomy. Br J Surg 2003;90:222-226.

59 Morinaga K, Hacuda K, Ikeda T: A novel therapy for internal hemorrhoids: Ligation of the hemorrhoidal artery with a newly devised instrument (Moricorn) in conjunction with a Doppler flowmeter. Am J Gastro 1995;90: 610-613.

60 Corman ML, Gravie JF, Hager T, Loudon MA, Mascagni D, Nystrom PO, Seow-Choen F, Abcarian H, Marcello P, Weiss E, Longo A: Stapled haemorrhoidopexy: A consensus position paper by an international working party - indications, contra-indications and technique. Colorectal Dis 2003;5:304-310.

61 Longo A: Treatment of hemorrhoids disease by reduction of mucosa and haemorrhoidal prolapse with a circular suturing device: A new procedure; in Proceed 6th World Congr Endoscop Surg, Rome, June 3-6, 1998.

62 Cheetham MJ, Mortensen NJ, Nystrom P-O, Kamm MA, Phillips RK: Persistent pain and faecal urgency after stapled haemorrhoidectomy. Lancet 2000;356:730-733.

63 Sutherland LM, Burchard AK, Matsuda J, Sweeney L, Bokey El, Childs PA, Roberts AK, Waxman BP, Maddern GJ: A systematic review of stapled hemorrhoidectomy. Arch Surg 2002;137:1395-1406.

64 Cheetham MJ, Cohen CRG, Kamm MA, Phillips RKS: A randomized controlled trial of diathermy hemorrhoidectomy vs. stapled hemorrhoidectomy in an intended day-care setting with longer-term follow-up. Dis Colon Rectum 2003;46:491-497.

65 Smyth EF, Baker RP, Wilken BJ, Hartley JE, White TJ, Monson JRT: Stapled versus excision haemorrhoidectomy: Long-term followup of a randomised controlled trial. Lancet 2003;361:1437-1438.

66 George BD, Shetty D, Lindsey I, Mortensen $\mathrm{NJMcC}$, Warren BF: Histopathology of stapled haemorrhoidectomy specimens: A cautionary note. Colorectal Dis 2002;4:473-476.

67 Herold A, Kirsch J, Staude G, Hager T, Raulf F, Michel J: A German multicentre study on circular stapled haemorrhoidectomy. Colorectal Dis 2000;2:18. 